\title{
Pembuatan Media Cloud Storage dengan OwnCloud sebagai File Manajemen di JTIK
}

\author{
Agus Setiawan, Lutfi Muhammad \\ Program Studi Teknik Informatika \\ Politeknik Negeri Jakarta, \\ Depok, Indonesia \\ Aguszahran123@gmail.com, lutfi.muhammad.tik11@mhsw.pnj.ac.id
}

Diterima: 5 September 2015. Disetujui: 8 Oktober 2015. Dipublikasikan: November 2015

\begin{abstract}
Abstrak - Cloud Computing merupakan sebuah model komputasi atau computing, dimana hardware seperti prosesor, media penyimpanan, jaringan komputer, dan software menjadi abstrak, setiap layanan cloud computing membutuhkan akses internet. Cloud Storage merupakan salah satu bentuk dari cloud computing yang memberikan layanan untuk manajemen berkas berdasarkan user di dalam jaringan komputer. Manfaat yang diperoleh dari penggunaan Cloud Storage antara lain penyimpanan data, file sharing dan sinkronisasi sehingga dapat mengurangi resiko file. OwnCloud merupakan open source yang dirancang untuk membangun Cloud Storage oleh kehilangan data dan kemudahan dalam berbagi karena dasar-dasar itu perancangan dan pembuatan cloud management system di JTIK (Jurusan Teknik Informatika dan Komputer). Politeknik Negeri Jakarta sangatlah diperlukan agar dapat memudahkan penyimpanan data dan file sharing berupa tugas atau materi perkuliahan antara mahasiswa dan dosen.
\end{abstract}

Kata Kunci: cloud computing, cloud storage, owncloud.

\section{PENDAHULUAN}

Teknologi cloud merupakan teknologi yang menjadi trend pada masa kini dimana jaringan internet digunakan sebagai media penghubungnya. Cloud Storage merupakan media penyimpanan di awan (di internet) yang mulai marak digunakan pada dewasa ini, penyedia layanan Cloud Storage juga semakin banyak dan dengan tanpa biaya yang ditawarkan [1].

Di Politeknik Negeri Jakarta, teknologi Cloud Storage belum diterapkan sepenuhnya dan juga belum bisa dirasakan oleh seluruh akademisi didalamnya, begitu juga pada jurusan JTIK yang baru berdiri kurang dari 1 tahun. Penerapan Cloud Storage pada JTIK dipandang baik karena dapat membantu mahasiswa dan dosen dalam melakukan kegiatan belajar mengajar. Dosen dapat mengupload mata kuliah yang akan diajarkan pada mahasiswanya, dan mahasiswa dapat meng-upload dan mengirimkan tugas yang diberikan oleh dosen yang bersangkutan.

Penerapan Cloud Storage di JTIK dapat membantu setiap akademisi JTIK untuk mengakses data secara cepat tanpa harus bertatap muka antara dosen dengan mahasiswa atau sebaliknya. Selain itu dapat menghimpun setiap data mahasiswa dan dosen JTIK. Cloud Storage ini dapat dikembangkan dan diimplementasikan di server pusat PNJ nantinya. Adapun tujuan dari penelitian ini adalah:

1. Menghasilkan dan membuat media penyimpanan data atau Cloud Storage berbasis web dengan tampilan yang user friendly.

2. Membantu civitas jurusan teknik informatik dan komputer dalam penyimpanan data secara digital.

3. Meningkatkan efektifitas dalam pengumpulan tugas dan juga pembagian mata kuliah.

\section{TINJAUAN PUSTAKA}

\section{A. Cloud Computing}

Cloud computing adalah sebuah model komputasi/computing, dimana sumber daya seperti processor/computing power, storage, network, dan software menjadi abstrak dan diberikan sebagai layanan di jaringan/internet menggunakan pola akses remote [2]. Model billing dari layanan ini umumnya mirip dengan modern layanan publik. Ketersediaan on-demand sesuai kebutuhan, mudah untuk dikontrol, dinamik dan skalabilitas yang hampir tanpa limit adalah beberapa atribut penting cloud computing [3].

Terdapat 5 karakteristik sehingga sebuah sistem dapat dikatakan sebagai sistem cloud computing [4], yaitu: 


\section{a. Resource Pooling}

Sumber daya komputasi (storage, CPU, memory, network bandwith, dll) yang dikumpulkan oleh penyedia layanan (service provider) untuk memenuhi kebutuhan banyak pelanggan dengan model multi-tenant. Sumber daya komputasi ini bisa berupa sumber daya fisik ataupun virtual dan juga bisa dipakai secara dinamis oleh para pelanggan untuk mencukupi kebutuhannya.

\section{b. Broad Network Access}

Kapabilitas layanan dari cloud provider tersedia lewat jaringan dan bisa diakses oleh berbagai jenis perangkat, seperti smartphone, tablet, laptop, workstation, dll.

\section{c. Measured Service}

Tersedia layanan untuk mengoptimasi dan memonitor layanan yang dipakai secara otomatis. Dengan monitoring sistem ini, kita bisa melihat beberapa resources komputasi yang telah dipakai, seperti bandwith, storage, jumlah pengguna aktif, dsb. Layanan monitoring ini sebagai bentuk transparansi antara cloud provider dan cloud consumer.

\section{d. Rapid Elacticity}

Kapabilitas dari layanan cloud provider bisa dipakai oleh cloud consumer secara dinamis berdasarkan kebutuhan. Cloud consumer bisa menaikkan atau menurunkan kapasitas layanan. Kapasitas layanan yang disediakan ini biasanya tidak terbatas, dan service consumer bisa dengan bebas dan mudah memilih kapasitas yang diinginkan setiap saat [5].

\section{e. Self Service}

Cloud consumer bisa mengkonfigurasikan secara mandiri layanan yang ingin dipakai melalui sebuah sistem, tanpa perlu interaksi manusia dengan pihak cloud provider.

\section{f. OwnCloud}

OwnCloud merupakan suatu perusahaan dengan proyeknya yaitu OwnCloud project. OwnCloud yang merupakan salah satu open source untuk membangun cloud computing. Open source ini dirancang dengan beberapa sistem managemen database, termasuk MySQL, MariaDB, SQLite, Oracle Database dan PostgreSQL [6]

Selain itu OwnCloud merupakan open source yang fleksibel yaitu dapat digunakan pada Linux, Macintosh, dan Windows. Penulis menggunakan OwnCloud dikarenakan mudahnya pencarian referensi dan penulis hanya mengetahui OwnCloud sebagai open source penunjang pembuatan media penyimpanan di Jurusan Teknik Informatika dan Komputer ini.

\section{PERANCANGAN DAN REALISASI UML}

Selain admin dapat memiliki akses untuk login dan logout, admin juga bisa mengontrol dan membuat user. Pada saat membuat user, admin dapat membatasi kapasitas yang dimiliki oleh user dan juga mengkelompokan user berdasarkan grup (mahasiswa dan dosen), dan admin juga dapat melihat log (aktivitas) yang dilakukan oleh user. Detil perancangan pada admin terlihat pada Gambar 1-6.

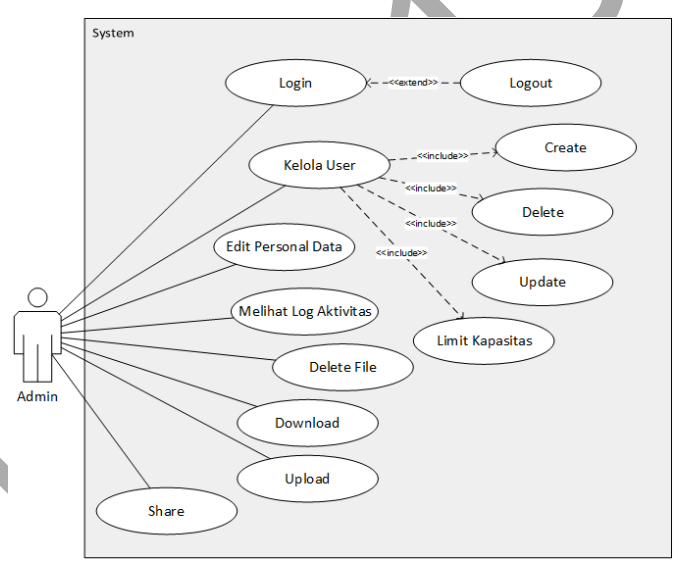

Gambar 1. Use Case Admin

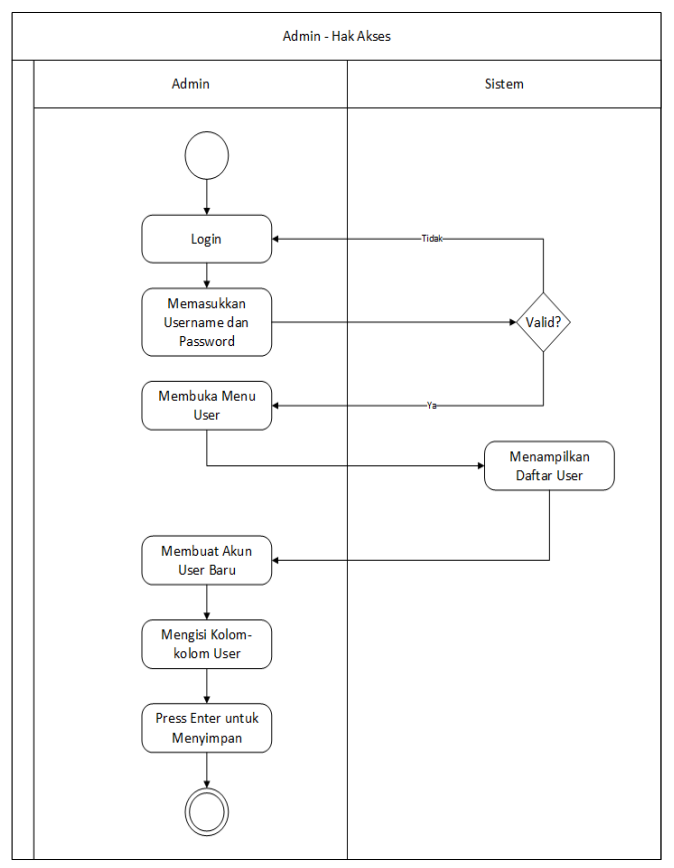

Gambar 2. Activity Login Admin 


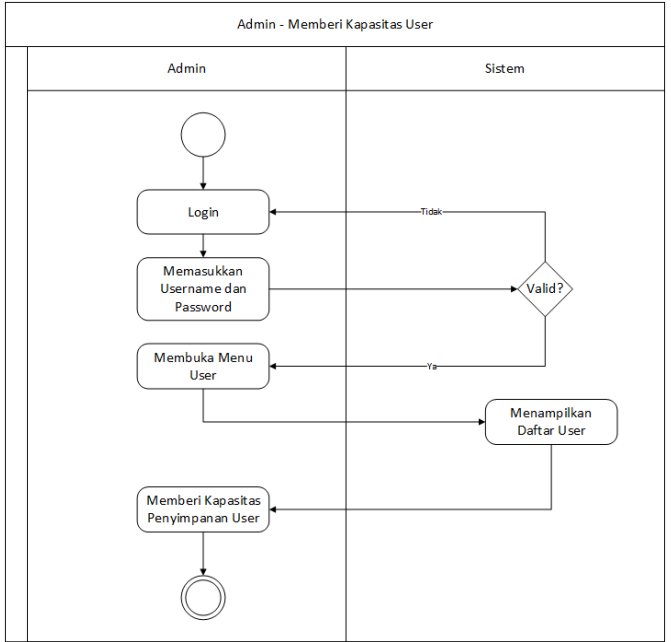

Gambar 3. Activity Kapasitas User

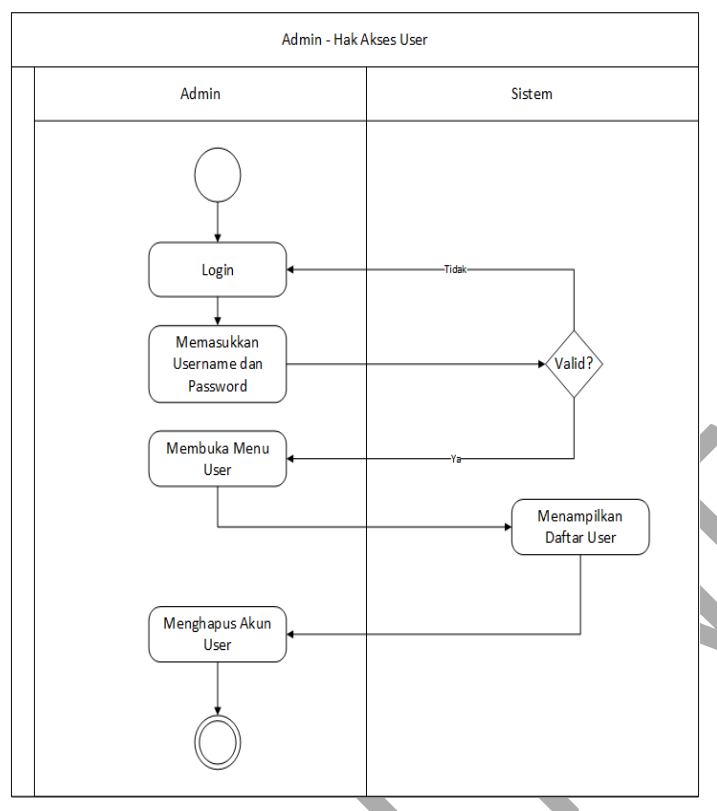

Gambar 4. Activity Hapus User

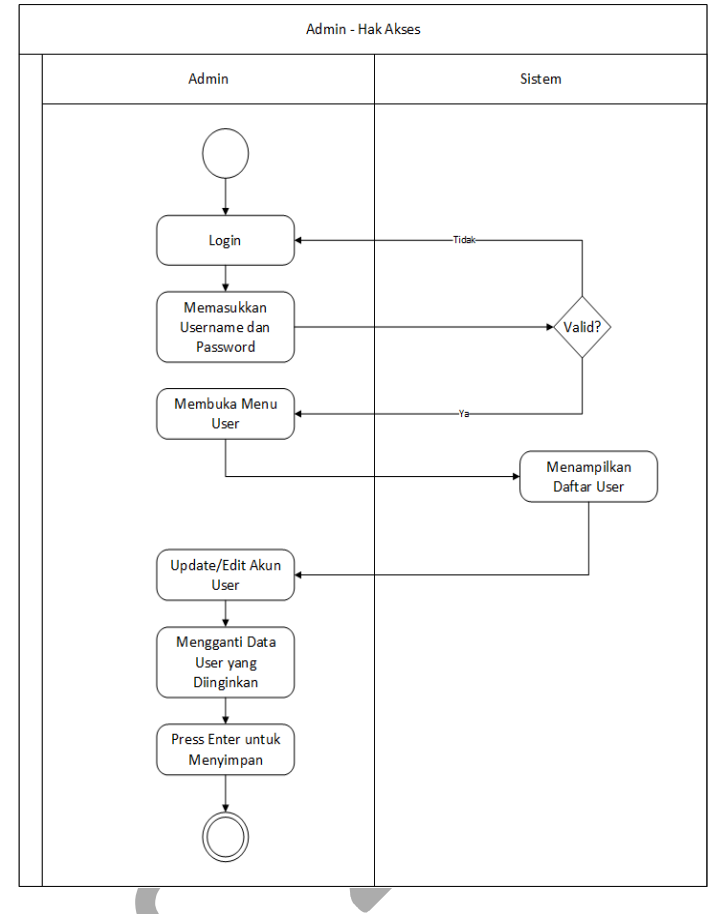

Gambar 5. Activity Update User
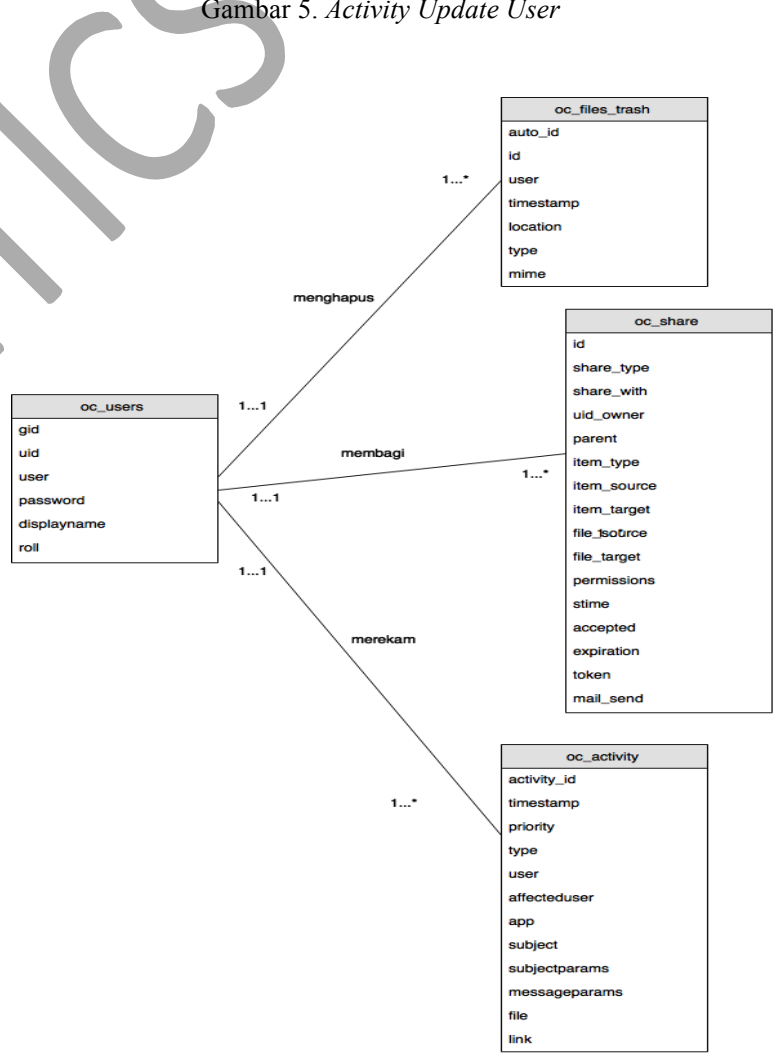

Gambar 6. ERD (Entity Relationship Diagram) 


\section{A. Realisasi Program Aplikasi}

Realisasi program aplikasi adalah tampilan asli dan nyata yang sudah jadi. Tampilan ini sudah dapat berfungsi dan sudah nyata prosesnya sesuai dengan cloud computing. Gambar 7 adalah tampilan Realisasi dari Cloud TIK :Login.

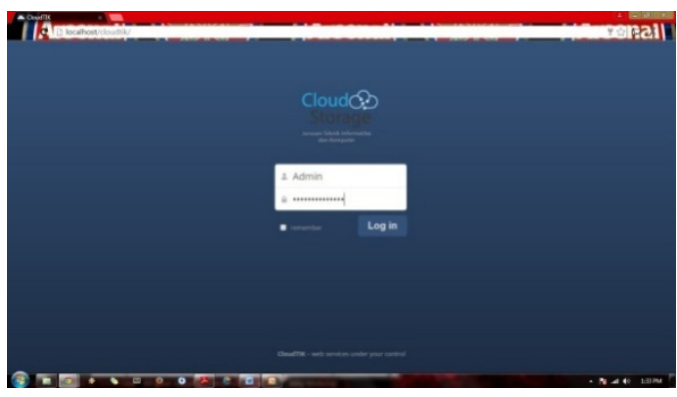

Gambar 7. Halaman Login

\section{a) Dashboard}

Gambar 8 adalah tampilan dashboard admin.

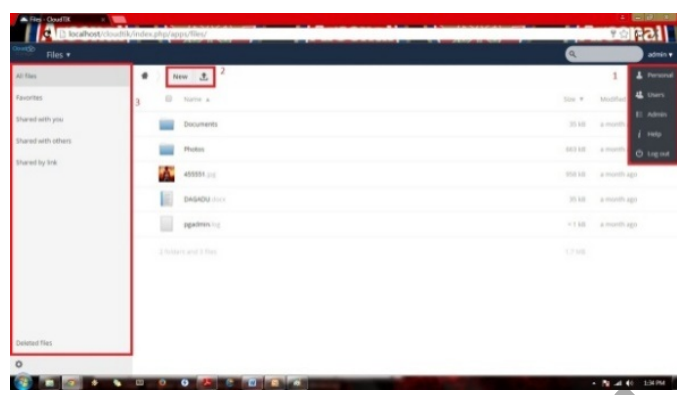

Gambar 8. Dashboard Admin

b) Daftar Tugas

Gambar 9 adalah laman tampilan personal data

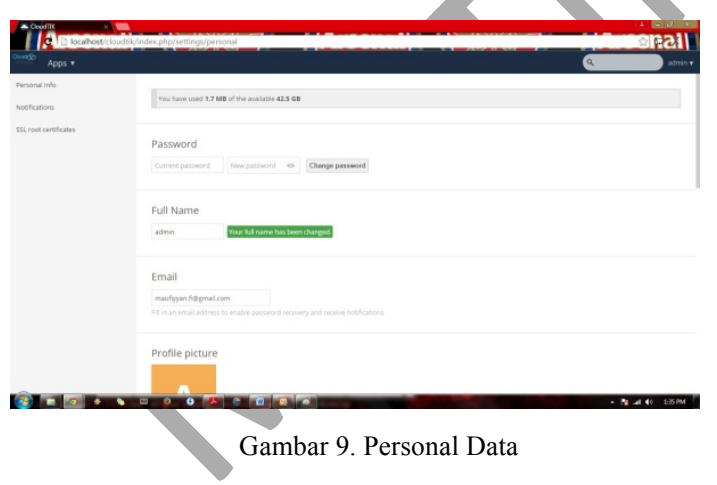

c) Tambah Tugas

Gambar 10 adalah tampilan laman CRUD user.

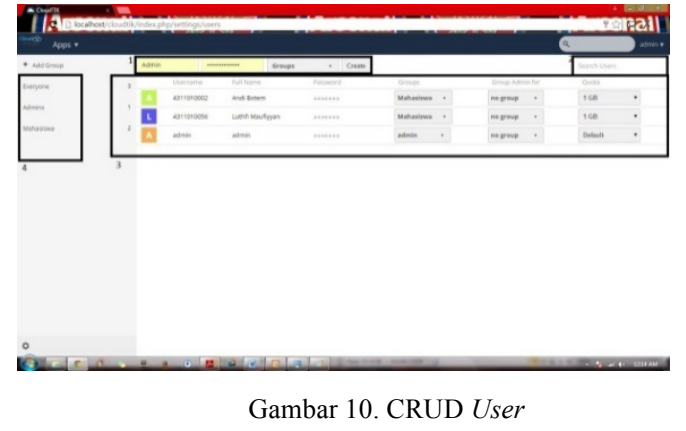

\section{B. Pengujian}

Tabel 1 merupakan daftar skenario pengujian yang dilakukan untuk menguji Admin di Cloud TIK dengan menggunakan Black Box. Pengujian black box berfungsi pada persyaratan fungsional perangkat lunak [7].

TABEL 1. SKENARIO PENGUJIAN

\begin{tabular}{ccc}
\hline Item Uji & Detail Penggunaan & Pengujian \\
\hline Login & Verifikasi Username & Black box \\
\cline { 2 - 3 } & Verifikasi Password & Black box \\
\hline Upload & Meng-upload data & Black box \\
\hline Share & Share data & Black box \\
\hline Download & Download data & Black box \\
\hline Delete & Delete data & Black box \\
\hline CRUD & Create User & Black box \\
\cline { 2 - 3 } & Read User & Black box \\
\cline { 2 - 3 } & Update User & Black box \\
\cline { 2 - 3 } & Delete User & Black box \\
\cline { 2 - 3 } & $\begin{array}{c}\text { Pembatasan kapasitas } \\
\text { penyimpanan data }\end{array}$ & Black box \\
\cline { 2 - 3 } & Membuat Grup User & Black box \\
\hline Personal & Edit personal data & Black box \\
\hline
\end{tabular}

C. Analisis Data

Dari hal-hal yang ingin dicapai pada perancangan sistem ini, diperoleh analisa keberhasilan sebagai berikut:

1) Sistem cloud computing Jurusan TIK Politeknik Negeri Jakarta atau disebut dengan Cloud TIK dapat dijadikan salah satu alternatif untuk membantu membagikan mata kuliah dari dosen ke mahasiswa, membantu mahasiswa mengumpulkan tugas, dan juga membantu bagi para pengguna yaitu mahasiwa dan dosen untuk berbagi data.

2) Pada perancangan sistem cloud computing ini ditujukan hanya kepada mahasiswa dan dosen. Namun, tidak menutup kemungkinan sistem ini 
dapat digunakan oleh staf-staf Teknik Informatika bila diperlukan.

3) Sistem selalu menampilkan notifikasi berupa dialog dalam setiap keputusan yang diambil oleh admin seperti share file, mengunggah file, perubahan personal data, membuat folder, hapus file, mengunduh file serta fitur-fitur admin yang lainnya.

4) Dengan adanya notifikasi maka dapat dikatakan bahwa pembangunan sistem cloud computing ini bebas kesalahan dan secara fungsional mengeluarkan hasil yang sesuai dengan yang diharapkan.

\section{IV.KESIMPULAN}

Sistem cloud computing di Jurusan TIK Politeknik Negeri Jakarta atau Cloud TIK adalah sistem berbasis web dengan menggunakan OwnCloud sebagai kerangkanya yang berguna untuk berbagi data antar civitas Jurusan TIK Politeknik Negeri Jakarta serta juga berguna untuk membagikan mata kuliah dan mengumpulkan tugas. Berdasarkan hasil pembahasan selama melakukan perancangan maka diperoleh beberapa kesimpulan, di antaranya:

1. Admin pada sistem Cloud TIK ini dalam perancangannya ditujukan untuk membuat akun untuk pengguna, memberikan kapasitas penyimpanan data bagi pengguna, membuat grup yang terdiri dari dosen, mahasiswa, jurusan, dan semester.

2. Sistem Cloud TIK yang dihasilkan dapat membantu dosen dan mahasiswa untuk berbagi data seperti tugas dan mata kuliah. Namun tidak menutup kemungkinan sistem ini juga dapat digunakan oleh staf Jurusan TIK Politeknik Negeri Jakarta bila diperlukan.

3. Sistem Cloud TIK ini menyediakan berbagai fasilitas cloud computing yang semestinya seperti unggah file, unduh file, sharing file, hapus file, membuat folder baru.

\section{REFERENSI}

[1] Yaser Jararweh, Moath Jarrah, Mazen kharbutli, Zakarea Alshara, Mohammed Noraden Alsaleh, Mahmoud AlAyyoub, CloudExp: A comprehensive cloud computing experimental framework, Simulation Modelling Practice and Theory, Volume 49, December 2014, Pages 180-192.

[2] Marisol García-Valls, Tommaso Cucinotta, Chenyang Lu, Challenges in real-time virtualization and predictable cloud computing, Journal of Systems Architecture, Volume 60, Issue 9, October 2014, Pages 726-740.

[3] Purbo, Onno W. 2011. Petunjuk Praktis Cloud Computing Menggunakan Open Source. IT CAMP 2011.

[4] Douglas Heaven, Personal clouds let you take control of your own data, -New Scientist, Volume 218, Issue 2919, I June 2013, Page 22.

[5] Melike Yigit, V. Cagri Gungor, Selcuk Baktir CloudComputing for Smart Grid applications, Computer Networks, Volume 70, 9 September 2014, Pages 312-329.

[6] Hamdan, Rangga. 2014. Apa Itu OwnCloud. http://www.ranggahamdan.com/2014/10/12/apa-ituowncloud/ [29 Juni 2015].

[7] Nidhra, Srivinas, \& Dondeti, Jagruthi. 2012. Black Box and White Box Testing Techniques - A Literature Review. International Journal of Embedded Systems and Applications (IJESA), 2(2), 1-2. 